\title{
Analysis of Longitudinal Deposition in Reservoir Confluence
}

\author{
Tao Yan ${ }^{1,}$, Hui Huang ${ }^{1,2, b}$ \\ ${ }^{1}$ Key Laboratory of Engineering Sediment of Ministry of Communications, Tianjin Research Institute \\ for Water Transport Engineering,Tianjin, 300456, China \\ ${ }^{2}$ College of Harbour, Coastal and Offshore Engineering, Hohai University, Nanjing, 210098, China \\ aemail: yantao198807@126.com, bemail:rainfull_hh@163.com
}

Keywords: Reservoir Confluence; Deposition Pattern; Hydrodynamic Conditions; Dual Backwater Effect

\begin{abstract}
The erosion basis in reservoir confluence, with the characteristic of dual change, resulted in special longitudinal deposition patterns. Based on field data, longitudinal deposit patterns of mainstream and tributary in reservoir confluence was studied and two special tributary deposition patterns - adverse cone and cone-adverse cone were proposed. Considering the operating mode of reservoir and backwater effect, variety of hydrodynamic conditions formed different deposition patterns of tributary and mainstream. It was revealed dual backwater effect is the internal mechanism of different deposition pattern in reservoir confluence.
\end{abstract}

\section{Introduction}

Reservoirs destroy the equilibrium of silting-scouring condition in natural rivers. Due to the backwater effect, deposit occurred. While sediment-laden flow from mainstream(tributary) moving forward to the dam, the erosion basis changes because of reservoir operating; as the flow in mainstream or tributary rises during flood period and falls during dry season, backwater effect between mainstream and tributary caused the secondary change of erosion basis, and then special longitudinal deposition patterns are formed. Informed researches about reservoir confluence deposition mostly focus on tributary confluence mouth bar, such as the formation condition [4], the source of sediment [5]. Those studies focus more on natural confluences [6-8], while deposition pattern in reservoir confluence usually be ignored. Reservoir confluence deposition as the important branch of reservoir deposition, study on it is not only the supplementary to research on reservoir deposition, but also explaining the cause of deposition from the angle of dynamics.

\section{Mainstream Hump Deposition}

When deposition occurs in sediment-laden tributary confluence, the mainstream located in confluence becomes hump pattern and the river bed elevation nearby tributary estuary is obviously higher than up and down stream. Statistics show that mainstream hump longitudinal deposition is common, such as Mangniu River confluence estuary in Baishi Reservoir [9], Yao River confluence estuary in Liujiaxia Reservoir[1] and Ceng River-Yuan River confluence estuary in Hanjiang Area of Danjiangkou Reservoir[4]. See Figure1.

Hump's convex vertex in Baishi Reservoir locates in tributary confluence estuary, however in Danjiangkou Reservoir, it locates upper hump's vertex of Yuan River confluence estuary and lower hump's vertex of Ceng River confluence estuary. Origin of vertex location being different lies in comparison and contrast of hydrodynamic condition during the deposition period when sediment-laden flow runs into confluence. 


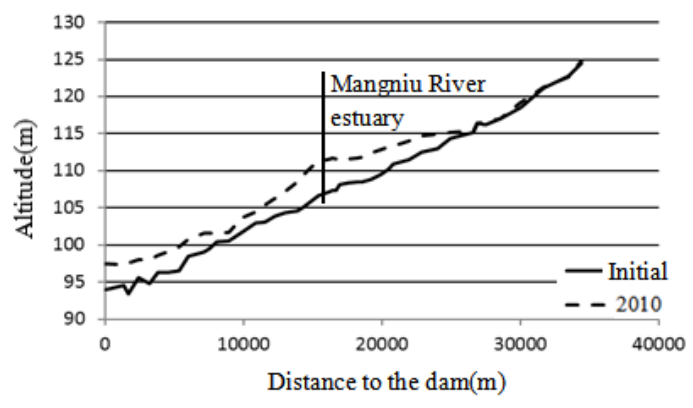

(a)Mangniu River confluence estuary in Baishi Reservoir

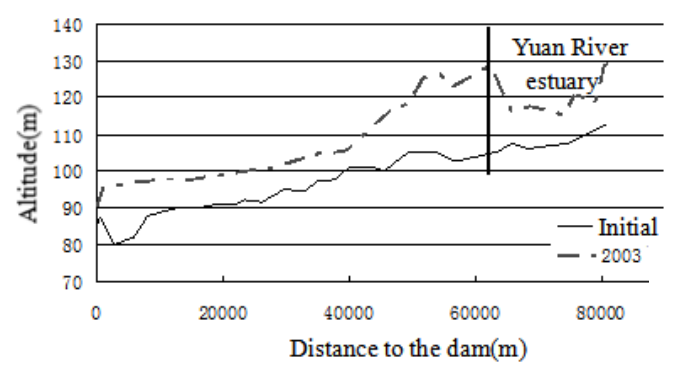

(c)Yuan River confluence estuary in Hanjiang Area of Danjiangkou Reservoir

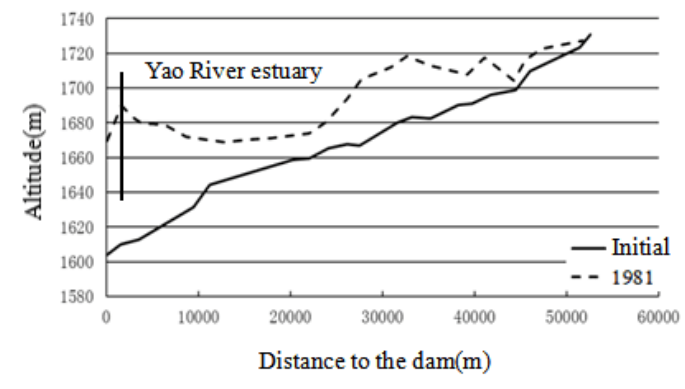

(b)Yao River confluence estuary in Liujiaxia Reservoir

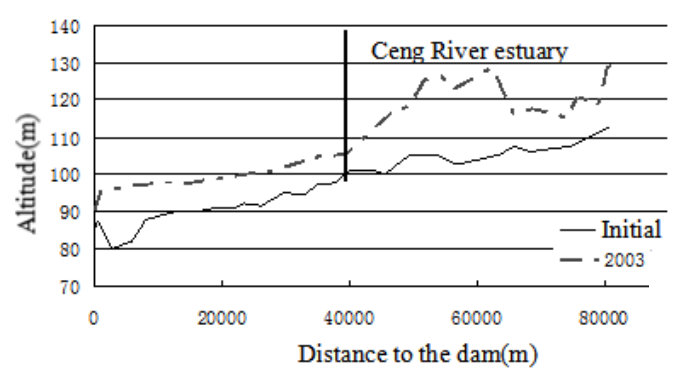

(d)Ceng River confluence estuary in Hanjiang Area of Danjiangkou Reservoir of mainstream in reservoir confluence

Table 1 calculated average annual discharge of above tributary and mainstream in reservoir confluences, we can see humped deposition is formed in tributary confluence estuary and the corresponding average annual discharge ratio (tributary discharge/total discharge) is well above than that appears in up-down stream of confluence estuary.

Table 1 Average annual discharge of tributary and mainstream in reservoir confluences

\begin{tabular}{|c|c|c|c|c|}
\hline reservoir confluences & $\begin{array}{c}\text { average annual } \\
\text { discharge of } \\
\text { tributary } \\
{\left[\mathrm{m}^{3} / \mathrm{s}\right]}\end{array}$ & $\begin{array}{c}\text { average annual } \\
\text { discharge of dam } \\
\text { site } \\
{\left[\mathrm{m}^{3} / \mathrm{s}\right]}\end{array}$ & $\begin{array}{c}\text { Tributary } \\
\text { discharge } \\
\text { ratio } \\
{[\%]}\end{array}$ & Statistical years \\
\hline $\begin{array}{c}\text { confluence in Baishi } \\
\text { Reservoir }\end{array}$ & 1.66 & 6.17 & 26 & $2001 \sim 2010$ \\
\hline $\begin{array}{c}\text { confluence in Liujiaxia } \\
\text { Reservoir }\end{array}$ & 149 & 814 & 18 & $1969 \sim 1996$ \\
\hline $\begin{array}{c}\text { confluence in } \\
\text { Danjiangkou Reservoir }\end{array}$ & $<3.17$ & $\begin{array}{c}1049 \text { (Hanjiang } \\
\text { Reservoir Area) }\end{array}$ & $<0.3$ & $1960 \sim 2003$ \\
\hline $\begin{array}{c}\text { confluence in } \\
\text { Danjiangkou Reservoir }\end{array}$ & 3.17 & $\begin{array}{c}1049 \text { (Hanjiang } \\
\text { Reservoir Area) }\end{array}$ & 0.3 & $1960 \sim 2003$ \\
\hline
\end{tabular}

\section{Tributary Longitudinal Deposition}

Under the dual-influence of water level in front of the dam and mainstream backwater effect, tributary erosion basis changes for the second time, as a result special patterns such as adverse cone and cone-adverse cone formed.

Adverse Cone. Mainstream flowing backward into tributary in flood season or lateral sediment transport arising from deposition in reservoir mainstream moving tributary confluence estuary, will generate deposition under a certain thickness and range in tributary. With the increasing distance from tributary estuary, sediment thickness decreases gradually, the tributary gradient becomes negative and adverse cone is formed. Along with the silt bar growing for a long time, tributary will be cut off and become mouth bar in a certain height. Figure 2 shows the adverse cone deposition pattern of Danjiangkou Reservoir tributary-Yuan River and Guanting Reservoir tributary-Guishui 
River.

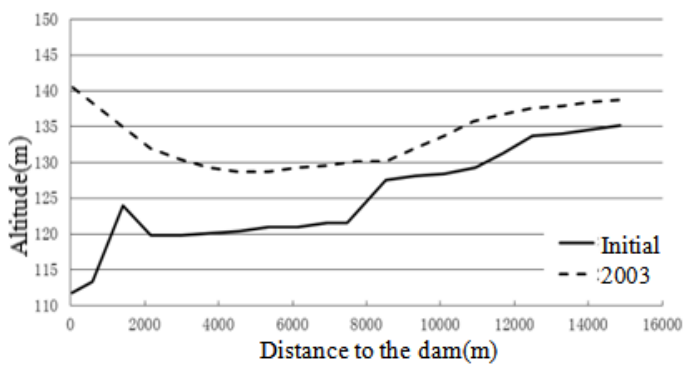

(a)Tributary deposition pattern of

Danjiangkou Reservoir tributary-Yuan River

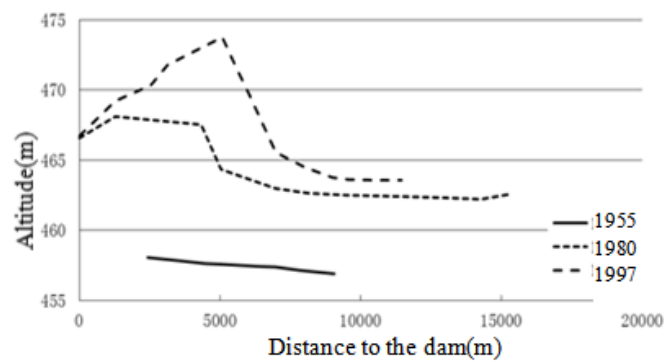

(b)Tributary deposition pattern of Guanting Reservoir tributary-Guishui River

Fig.2 Tributary deposition pattern of reservoir confluence-adverse cone

Cone-adverse Cone. Mainstream flowing backward into tributary in flood season leads to deposition adverse cone. When tributary dynamic conditions grow strong, deposition adverse cone will become cone or develop to the direction of cone under tributary flow effect. When mainstream intrusion enhances again, deposition cone will develop to adverse cone. River longitudinal pattern changing frequently, leads to the formation of cone-adverse cone in a certain distance. Table2 shows gradients of above tributaries from 2006 to 2010. By analysing interannual gradient, it shows in the range of Zhenshui Estuary to $7 \mathrm{~km}$ upstream, the gradient reduced from $0.61 \%$ o to $-1.08 \%$ o between 2006-2010 and the pattern was adverse cone, while it increased from -1.09\% to - $0.54 \%$ in 2011 and the pattern developed to the direction of cone.

Table 2 various of gradients in cone and adverse cone pattern unit:\%o

\begin{tabular}{|c|c|c|c|c|c|c|r|}
\hline tributary & range & 2006 & 2007 & 2008 & 2009 & 2010 & 2011 \\
\hline & & \multicolumn{7}{|c|}{ Absolute value } \\
\cline { 3 - 8 } Zhenshui & \multirow{3}{*}{$0-7000 \mathrm{~m}$} & 0.61 & 0.27 & 0.14 & -0.13 & -1.08 & -0.54 \\
\cline { 3 - 8 } & & \multicolumn{7}{|c|}{ Relative value } \\
\cline { 3 - 8 } & & - & -0.34 & -0.13 & -0.27 & -0.95 & 0.54 \\
\hline \multirow{3}{*}{$\begin{array}{c}\text { Yanxi } \\
\text { River }\end{array}$} & \multirow{3}{*}{$0-2200 \mathrm{~m}$} & -0.44 & 0.3 & 0.19 & -0.23 & 0.36 & 0.24 \\
\cline { 3 - 8 } & & \multicolumn{7}{|c|}{ Relative value } \\
\cline { 3 - 8 } & & - & 0.75 & -0.11 & -0.42 & 0.59 & -0.12 \\
\hline
\end{tabular}

Note: Relative value is the difference between gradients of adjacent two years, + represents increase and - represents decrease.

Gradient of Yanxi River fluctuates fiercely. In 2006, its pattern was adverse cone and gradient was $-0.44 \%$. The tributary developed into cone deposition during 2007-2008. From 2006 to 2007, the gradient increased, while it decreased during 2007-2008, reduced further to $-0.23 \%$ during 2008-2009 and the deposition pattern was deserve cone. During 2010-2011, deposition pattern of Yanxi River developed into cone and gradient increased to $0.24 \%$ eventually.

\section{Analysis of Deposition Dynamic Conditions}

Different deposition pattern in reservoir confluence mainstream and tributary is closely related to corresponding hydrodynamic conditions. For reservoir confluence that interannual discharge changes little, hydrodynamic conditions is key factor to scouring-silting variation and main reason for longitudinal deposition change. Reservoir confluence hydrodynamic conditions are strikingly affected by reservoir operation mode and backwater effect between mainstream and tributary.

Reservoir Operation Mode. Reservoir operation modes, including interannual operation mode in different period and annual scheduling mode in the same period, lead to the change in submerged depth, and above differences between dynamic condition affect the silting-scouring volume in 
reservoir confluence. Figure 3 shows average annual silting-scouring volume from tributary Wei River estuary to Lintong Area in San menxia reservoir in different operation period. Under the retain water-flood detention operation mode, deposition develops quickly in reservoir confluence tributary, while operating at low water level in flood season can release deposition validly with clear water storage and waste water release mode. If the operation water level declines further to $326 \mathrm{~m}-318 \mathrm{~m}$, tributary will return to nature and be scoured. Tributary having diverse characteristics of erosion and deposition in different period, will shows diverse longitudinal deposition.

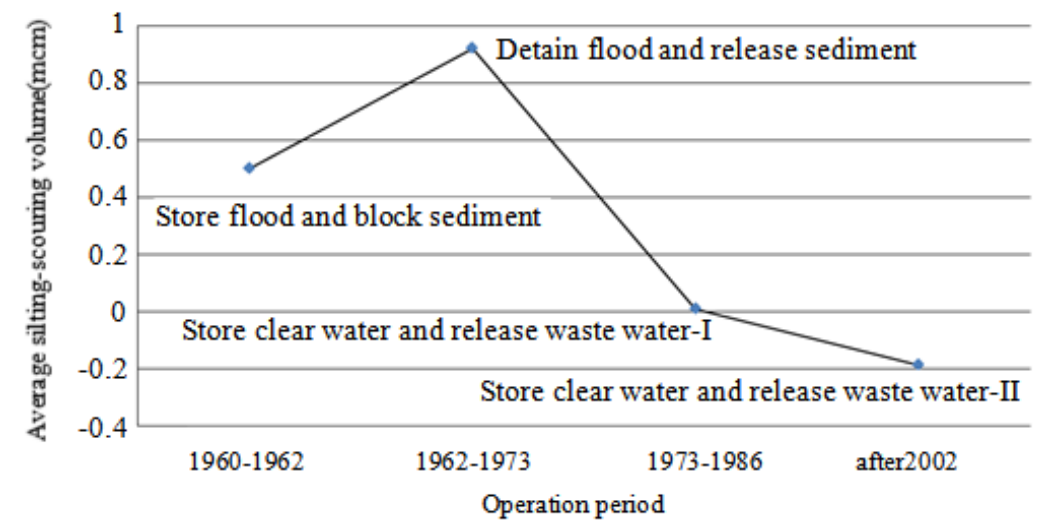

Fig.3 silting-scouring volume of tributary reach in San menxia reservoir

Backwater Effect between Mainstream and Tributary. When water level in front of dam keeps constant, the change of discharge, what we call backwater effect between mainstream and tributary, causes the water level changing in mainstream and tributary of upper confluence and influences the longitudinal changing feature of current speed. Intensity and duration are two basic factors of backwater effect. The stronger backwater effect is, the quicker current speed reduces. Confluence ratio is a quantitative indicator reflecting intensity of backwater effect. Usually confluence ratio is defined as the ratio between tributary discharge and total discharge of mainstream and tributary.

Table 3 shows the confluence ratio of main sediment transport period in Baishi Reservoir Mangniu River and Daling River in 2003,2006 and 2009. When $\mathrm{R} \geq 0.9$ in 2003 and 2009, tributary had the strongest backwater effect on mainstream, the current speed reduced much more quickly and the effect lasts for a long time. In 2003 , the ratio that $\mathrm{R} \geq 0.5$ was more than $40 \%$, while it was only $12.3 \%$ in 2006 , which showed that intensity and duration of backwater effect occupied a dominate position.

Table 3 intensity and duration of backwater effect in flood season of confluence

\begin{tabular}{|c|c|c|c|c|c|}
\hline \multirow{2}{*}{ Time } & \multicolumn{5}{|c|}{ Ratio of days of occurrence to whole days in flood season / \% } \\
\cline { 2 - 6 } & $R \geq 0.9$ & $R \geq 0.7$ & $R \geq 0.5$ & $R \geq 0.3$ & $R \geq 0.1$ \\
\hline 2003 & 4.1 & 24.6 & 41.8 & 76.2 & 82 \\
\hline 2006 & 0.8 & 4.9 & 12.3 & 49.2 & 85.2 \\
\hline 2009 & 8.2 & 20.5 & 32 & 39.3 & 57.4 \\
\hline
\end{tabular}

\section{Conclusion}

(1) Influenced by second change of erosion basis, special longitudinal deposition patterns are formed in reservoir confluence, like hump deposition in mainstream, adverse cone deposition and cone-adverse cone deposition in tributary.

(2) Different operation mode of reservoir leads to the change of submerged depth. Backwater effect between mainstream and tributary causes the water level changing in mainstream and tributary of upper confluence. These make erosion basis in reservoir confluence change twice, and current speed longitudinal characteristics change along with it, than various deposition patterns are formed. 


\section{References}

[1] JIAO En ze. The Yellow River Reservoir Sediment[M].Zhengzhou: The Yellow River Water Conservancy Press .2004

[2] HAN Qi-wei, YANG Xiao-qing. A review of the research work of reservoir sedimentation in China[J]. Journal of China Institute of Water, 1(3): 169-178, 2003

[3] Tai Shucai, Cui Chengzhang. Using Principal Component Analysis and Cluster Analyis to Study the Category of Reservoir Deposition Pattern[J]. Journal of Sediment Research, 2:77-82,1996.

[4] ZHANG Hou-yu, LIN Yun-fa, YANG De-an .etc. Deposition Analysis on Danjiangkou Reservoir Area in Han River[J]. Journal of Yangtze River Scientific Research Institute, 27(9):1-5,2010.

[5] ZHANG Junhua, MA Huaibao, WANG Ting .etc. Model test of water intrusion and deposition morphology of tributary in Xiaolangdi Reservoir[J].Advances in Science and Technology of Water Resources, 33(2): 1-5, 2013.

[6] WANG Ping, ZHANG Yuan-feng, HOU Su-zhen .etc. Experimental Study on the Process of the Hyperconcentrated Flood of the Tributaries' Merging into the Upper Yellow River and the Deposition Pattern in the Confluence[J]. Journal of Sichuan University (Engineering Science Edition), 45(5): 34-42,2013.

[7] GUO Zhi-xue, YU Bin, CAO Shu-you .etc. Experimental Study on Variation Law nearby the Confluence of Debris Flow Discharging into a River[J]. Journal of Hydraulic Engineering, 1:33-37,2004.

[8] CHEN De ming, WANG Zhao yin, HE Yun. Experimental Study on the Fluvial Process of Debris Flow Discharging into a River[J]. Journal of Sediment Research, 3:22-28,2006.

[9] ZHU Xiao-kai, WANG Zai-xiang, YANG Xiao-bo.Observation and Analysis of Sediment Deposition in Initial Operation of Baishi Reservoir [J]. Technology of Soil and Water Conservation, 1:7-9, 2010 